\title{
Conceptualization and Operationalization: Utility of Communication Privacy Management
}

\section{Theory}

Sandra Petronio ${ }^{1}$ and Jeffrey T. Child ${ }^{2}$

Addresses

${ }^{1}$ Center for Communication Privacy Management, UL 2102, IUPUI, 755 W Michigan St, Indianapolis, IN 46202 USA

${ }^{2}$ School of Communication Studies, Kent State University, Box 5190, Kent, OH 44242-0001 USA

Corresponding author: Petronio, Sandra (petronio@iupui.edu)

This is the author's manuscript of the article published in final edited form as:

Petronio, S., \& Child, J. T. (2020). Conceptualization and operationalization: Utility of communication privacy management theory. Current Opinion in Psychology, 31, 76-82. https://doi.org/10.1016/j.copsyc.2019.08.009 


\section{Conceptualization and Operationalization:}

Utility of Communication Privacy Management Theory

\section{Abstract:}

Communication Privacy Management (CPM) theory explains one of the most important, yet challenging social processes in everyday life, that is, managing disclosing and protecting private information. The CPM privacy management system offers researchers, students, and the public a comprehensive approach to the complex and fluid character of privacy management in action. Following an overview of Communication Privacy Management framework, this review focuses on recent research utilizing CPM concepts that cross a growing number of contexts and illustrates the way people navigate privacy in action. Researchers operationalize the use of privacy rules and other core concepts that help describe and explain the ups and downs of privacy management people encounter.

Keywords: Privacy, Boundaries, Communication Privacy Management theory, Rules, Disclosure, Turbulence

\section{Introduction}

The New York Times' Privacy Project has propelled contemplation and consideration about the nature of privacy [1]. As this project notes, there are a number of ways that people think about privacy. Yet, it seems that the cry for help rings true every day. How can we make sense of the current status of privacy? Some researchers frame the notion of privacy as paradoxical [2] others use the concept of privacy calculus [3]. The most common research revolves around security and 
protection of privacy $[4,5]$. Others concentrate on preserving privacy [6] and there are many who focus on legal issues regarding privacy [7]. There is also considerable amount of research studying issues surrounding data protection [8] and the impact social media and all the new technologies have on privacy [9].

With all of the attention given to privacy, there is a need to examine how people actively manage information they consider private in everyday life. To understand active management of private information, this review focuses on conceptual and operational privacy management that is central to Communication Privacy Management Theory (CPM) published under the title of "Boundaries of Privacy: Dialectics of Disclosure" as a book in 2002 [10] published by Petronio, who has published on privacy since 1986 [11-16]. The structure of CPM is grounded in core concepts and the explanatory power of sense-making that guide an understanding of privacy management according to CPM theory and research. Research citing CPM theory and research is substantial (see https://cpmcenter.iupui.edu/index.php/research/citation/).

The breadth of research utilizing of Communication Privacy Management (CPM) theory demonstrates its usefulness to understanding privacy in everyday life. The theoretical frame is guided by a very clear set of tenets built on previous research and theories, particularly Irwin Altman $[17,18]$. The early mission of CPM theory focused on determining a viable way to understand how to conceptualize and determine useful ways to operationalize the nature of privacy, and specifically, that of private information management. Much was learned during the early ventures into the nature of privacy. In particular, the important foundation Altman provided and his challenge to social behavioral researchers to engage in discovering more about the notion of privacy has provided a significant platform for the future ([17], p.6). Altman's early and significant foray into privacy set the stage for extending the conceptual and operational base 
in developing the next generation of understanding privacy through the lens of Communication Privacy Management theory.

\section{Conceptualizing CPM}

CPM theory recognizes that individuals believe that they own their private information and have the right to control that information [19]. Ownership is represented by metaphoric "privacy boundaries" that define where people house and protect their information [20,21]. CPM uses the identifier of "information owner" to represent rightful control of one's private information. In addition, selected co-owners are designated as "authorized co-owners" indicating the legitimacy of access. People believe they have control over their privacy boundaries and trust they have rights to grant who can have access and when their private information is off limits to others [22]. However, revealing or disclosing private information has potential risks that can lead to feelings of vulnerability for the owner [23]. Nevertheless, having even a "sense" of control is important because it can temper feelings of susceptibility.

When people want or need to disclose private information, they make judgments about who or whether they decide to open their privacy boundary to reach their goal of revealing or concealing their private information [24,25]. Once information owners make a choice to disclose or conceal private information, they use "privacy rules" to guide their management of privacy [26,27]. Informational owners make choices about their access using "privacy rule criteria" to drive privacy rule choices $[28,29,14]$. Core privacy rule criteria are stable and predictable factors of privacy regulation across time, such as the influence of culture on privacy management decisions. Catalyst privacy rule criteria are more variable factors that influence privacy choices, such as, when a person is unexpectedly caught off guard by a spouse who reveals "I have filed 
for a divorce." Catalyst privacy rules are often unpredictable. Rules that have been held for a long time can disappear given different needs. Taken together, the core and catalyst criteria account for anchor points in regulating privacy control issues and influence the way privacy boundaries function. [16].

The articulation of privacy rules and privacy boundaries becomes more complicated when there are multiple privacy boundaries to navigate. CPM argues that privacy boundaries are both singular, focused on one person's privacy boundaries and collective where there are multiple levels of privacy boundaries, such as, groups, family co-worker collective boundaries, and social media boundaries [30,31]. When there are multiple boundaries, there is a need for coordinating issues such as, privacy rules, level of privacy ownership, and privacy control to yield the most productive outcome for privacy management [32,33]. For example, family members might withhold information about their health issues with other members only to find that the family is upset that they were left out. The connectedness of collective boundary members often creates challenges of navigating privacy rules and boundaries parameters.

Because we do not live in a perfect world, CPM argues that people can make mistakes that impact communication privacy management in a number of ways. As a result, these situations create what CPM identifies as "privacy turbulence" [34,35]. Privacy turbulence is problematic because this condition can disrupt privacy rules, ownership, control, and privacy boundaries as well as existing privacy relationships [36,37]. While privacy turbulence has negative outcomes for the information owner and privacy relationships, some preliminary research suggests, that at times, a lesson is learned and the owner recalibrates privacy rules to prevent the experience again [38-42].

\section{Operationalizing CPM}


Several key component parts of the CPM management system and corresponding concepts are illustrated through CPM research articles. At times, researchers find that one or more of CPM concepts can be effectively used together. The categories include privacy boundaries, privacy rules, collectives, and privacy turbulence.

\section{Privacy Boundaries}

The metaphoric privacy boundaries represent a way to mark rightful ownership. The thickness of privacy boundaries indicates the degree of "boundary permeability," which is how much or little private information is disclosed to the extent that privacy owner grants or denies access to the owner's private information. Child and Starcher [43] explored the line between boundary permeability and control by studying the inter-relationships among mediated lurking, use of strategic ambiguity, and Facebook privacy management. Specifically, the study finds that when people are concerned about mediated lurking online they use strategically ambiguous messages (controlling both permeability and co-ownership levels) when interacting on social media as a mechanism to protect their privacy. Interestingly, when people are not concerned with mediated lurking, some respondents used strategically ambiguous messages to share more private information. As such, those respondents used strategically ambiguous messages on social media because they want network members to ask them to share more of what might be on their mind.

Likewise, McNealy and Mullis [44] found CPM boundary coordination rules influenced how users share, manage, and discuss on a gossip forum site. In this research, when people engaged in gossiping online, a co-ownership strategy used was placing a watermark on shared images. Doing so, identifies any gossip related images and content that might be further shared beyond the informational owner. People would also share some details about themselves in order to demonstrate that the information they were gossiping about online was authentic, like their 
credentials or professional position. These studies highlight how people actively manage privacy boundaries online.

Although privacy owners presume control rights over their private information, they also want selected others participating in their management according to the owner's rules. Informational owners want authorized co-owners to follow their privacy rule expectations, such as clarifying who else can know the private information (linkage rules), how much of the disclosed information can be shared with others (permeability rules), and the level of independent judgments the owner allows the co-owner to determine third-party access (control rules) $[10,45]$. Being granted access, the information owner expects the co-owner to abide privacy rules thus coordinating ownership and the expectation of control [46]. However, even when disclosers expect recipients to follow the owner's privacy rules, research is inconsistent on whether recipients do follow the rules [47].

The levels of control are regulated through privacy boundaries. The boundaries may be adjusted with low control when there are few restrictions on access, relative trust, and boundaries are more permeable. When the level of control is high, boundaries are thick, trust is low, and there are many restrictions [22]. For example, informational owners who wish to enact high levels of control tend to articulate privacy rules that are presumed to limit further sharing of private information by co-owners, such as “don’t tell anybody but. ..” [48]. Informational owners comfortable with low levels of control articulate privacy rules that give significant latitude to the co-owner in the future sharing of the co-owned information, such as "tell whoever you trust" or "I am comfortable with you sharing this with others." In a study of adoptee reunions, Scharp and Steuber [49] found adoptees expressed a need for birth mothers to serve as information guardians revealing desired information and concealing unwanted disclosures. The adoptee expected the 
birth mother to anticipate the adoptee's needs and adjust their boundary permeability appropriately. In a similarly complicated situation when parents participate in managing their child's chronic illness, Rafferty, Hutton, and Heller [50] found parents had to engage in active communication work designing messages for health professionals that would ordinarily be the patient's responsibility.

\section{Privacy Rule Regulation}

Understanding privacy rules offers an avenue to understand choices people make regarding disclosure or keeping information private. Focusing on high stress circumstances provides an important focus that affords insights not easily available. A recent article on miscarriages authored by Bute, Brann, and Hernandez [51] offers an excellent example. The study asked why people find it so difficult to discuss miscarriages even though miscarriages are a common experience. By focusing on how societal expectations intersect with privacy rules, the research shows that the societal-level privacy rules such as "keep it behind closed doors" or “don't announce a pregnancy too soon" shaped perceptions of how the respondents should talk or refrain from talking about their experience.

In studying how undocumented youths navigated the disclosure of their status, Kam, Fazio, and Murillo [52] found the youth used privacy rules to guide the process of disclosure of their status. In particular, undocumented youths opened up their privacy boundaries and discussed their undocumented status to receive support from others. Developing relationships allowed for a sense of security where these youths felt protected by others and where the youths felt a sense of acceptance by those in similar situations. The youth reported opening up their privacy boundaries about their undocumented status less often among nonfamily members than among members of their extended family networks. 
Privacy rules can be formed through socialization of pre-existing privacy rules or as the above research shows, privacy rules can emerge from new situations. For example, children are taught privacy rules that the family believes are important for them to learn. Likewise, individuals who join new groups or get new jobs likely find that there are privacy issues in the workplace that can challenge pre-existing privacy rule. Millham and Atkin [53] found that when placing a high value on private information, individuals tend to be less willing to disclose information while visiting online social networking sites. They are applying a "closed" rule in a venue that is predicated on encouraging "openness."

In a bi-national comparative study Liu and Wang [54] examine complex boundary management as individuals make decisions to disclose information (or not) on social network sites, where privacy control is limited, thereby making boundary management challenging, boundary turbulence more likely, and cultural differences manifest. They found that when individuals either had strong established group norms online or could make effective use of privacy settings, they experienced fewer privacy violations. The cultural variables of individualism and uncertainty avoidance led people from the United States (U.S.) and China to enact different privacy management practices. Among the Chinese social media users, concern about protecting others' privacy was a bigger issue whereas in the U.S. helping individual users deal with their own privacy ramifications was a more critical privacy management concern. Whether at work or in personal life, people often find they need to change existing privacy rules and clarify privacy rules expectations.

As CPM shows, privacy rules can become routinized over time thereby developing into "privacy rule orientations." Privacy rule orientations are ingrained in families, for example, where members have established a set of privacy rules with congruent rules held by the members. 
Although privacy orientations tend to be consistent in families there are times when members may have different needs or desires where changes in privacy rules are needed [55]. Rueter, Connor, Pasch, Anderson, Scheib, Koerner, and Damario [56] examined parents' privacy orientation when sharing information with children conceived by in vitro fertilization. This research found that when families had open privacy orientations, the sharing of information about in vitro fertilization positively relates to being comfortable with the knowledge communicated to the child. However, when the privacy orientation of the family was restricted in terms of communicating information to the child, the outcome negatively impacted the parentchild relationship.

\section{Collective Coordination Patterns}

The patterns of collective coordination have both consistencies and unique features (see [45] for an extensive discussion). Collective coordination is predicated on abiding mutually owned privacy rules and the agreed upon nature of privacy boundaries as defined by particular collective.

When privacy boundaries expand to incorporate collective others, there are external privacy boundary spheres that regulate access to private information and internal boundary spheres thereby controlling what private information cannot be disclosed to outsiders. In a study on privacy management on Facebook, De Wolf, Willaert and Pierson [57] found a gender difference in how people define the parameters of privacy management. In a youth organization, they found that women are more likely to use individual privacy management strategies and men were more likely to use group management strategies. An individual privacy management strategy involves articulating privacy rules for different people whereas a group strategy targets clarifying privacy expectations for the entire group to follow. Additional research on the use of individual verses 
group privacy management on social media is needed to better understand the dynamics of gender, privacy management, and strategies.

Families provide an illustration of managing internal privacy boundaries within collectives. Campbell-Salome [58] found that young adult women covered by their parents' health insurance preferred to be in control of their private health information even if they understood their parents had a right to co-ownership of the information as the policy holder. As a result of their preference for privacy and fear that their parents would learn of their use of "stigmatized health services" these women delayed healthcare, personally paid for covered services, and engaged in deception.

In another study on family transition, Brockhage and Phillips [46] examine how privacy boundaries shift when a sibling moves out of the home and siblings experience contradictions as they negotiate privacy rules. Several respondents reported increasing openness with siblings across time, yet many expressed the privacy rules were complex. For example, a respondent said he would tell his sister everything, then subsequently named topics that were off-limits with her. Others differentiated among family members sharing more information with siblings in the emerging adulthood period that is not intended to be shared with the entire family unit.

Osatuyi, Passerini, Ravarini, and Grandhi [59] focus on willingness to disclose sensitive personal information on social networking sites. This research shows that previous experiences with social networking sites increase the likelihood that individuals will disclose. Learning from experience, the disclosers were more willing to reveal private information on social networking sites. This article illustrates that aspects of privacy rules change based on experience. The catalyst of privacy infringement, for example, shifted the use of privacy rules to counterbalance the taken-for-granted assumptions about privacy on these sites. 


\section{Privacy Turbulence}

Although privacy turbulence, as a concept, has been a mainstay since the 2002 book on privacy management was published, with the exception of the 2003 article by Afifi [60] on feeling caught, only recently have researchers begun to investigate this concept. Privacy turbulence occurs when there is a breakdown in how regulation of privacy management results in disruptions of privacy rules, ownership, control, privacy boundaries, and privacy relationships.

One of the consistent issues that marks a state of privacy turbulence is the level and kind of disruptions that occur. Violations of recipient's private information is the most egregious and reflect situations that derive from third party disclosures. As such, recipients make judgments about how they need to navigate unexpected violations. A set of studies examined outcomes from third party encounters. They found that truth-telling and falsification marked ways people dealt with privacy violations [61]. In addition, Aloia [62] found that privacy turbulence, quantified as the number of people who received private information, was positively associated with anger, fear, and sadness. Thus, the intensity and types of privacy turbulence are experienced in number of situations.

When parents learn an unforeseen medical diagnosis about their child, there is a period of "anticipated turbulence" [63] as parents process information, experience uncertainty, and are emotionally challenged. This experience triggers privacy management as the parents make numerous decisions communicating information to the child, family members, and health professionals.

Facebook users often experience the need to readjust privacy rule preferences to effectively maintain desired privacy protection levels [38,39]. Individuals accomplish this by deleting 
previously posted materials when reviewing content that had been disclosed online. More often than not, people anticipate possible problems because of what they have shared rather than reacting to actual privacy breakdowns [38]. The primary reason people adjusted their privacy rules toward the greater protection of private information was to manage impressions more effectively to better protect their safety and personal identity. In addition, appeasing important relational partners was identified and so was preventing legal or disciplinary problems from occurring [38]. A follow-up study found whenever people were more permeable and open with their current privacy practices, they invariably used a range of the content deletion practices to maintain their privacy adequately [39]. These studies illustrate that people both attend to their social media disclosures and actively manage privacy to prevent further breakdowns from occurring.

Parental privacy invasion has been an important line of inquiry since 1994 and reflects ways turbulence occurs, such as parent-child tensions between privacy invasions and defenses [64]. Turbulent tensions play an important part in privacy management, particularly in high stress situations such as coping with bereavement [65], adult children handling their parent's infidelity [66], feeling caught in stepfamilies [60], and sexting. Reporting research on sexting, Walrave, Van Ouytsel, Ponnet, and Temple [67] highlight the risk of boundary turbulence with the complex intersection of intimate information, social media's characteristics, psychological dynamics, and the dialectical tensions experienced by the discloser and recipients as each considers sharing (or not sharing) co-owned information. As this overview of privacy turbulence suggests, researchers have made a strong start in unraveling the nature of privacy turbulence.

\section{Start of the Future}


In considering the utility of CPM theory and research by assessing the way that concepts were developed and subsequent research has been published, CPM proves to be a robust way to better understand active privacy management. CPM theory and research illustrate that different people often mark the same type of information as both private and public for different reasons. As such, active engagement with others in coordinating mutually understood privacy rules to follow can help in the prevention of privacy breakdowns when sharing information with others. People rely on their own preferences for sharing private information when dialogue and discussion about how to manage information disclosed between people does not occur which invariably leads to privacy breakdowns and turbulence. The CPM privacy management system has considerable apparatus to accommodate many issues arising with privacy. In the years of use, patterns have emerged to further expand the scope of knowledge. In considering private information, one of the patterns emerging is fluidity in what constitutes the meaning of private information. The conditions of private information can change across ownership of information, life span, the kind of information, and more.

Another pattern focuses on the centrality of others. Essentially, only when others are involved is there a need to "manage private information." Dialectal tensions prove significant in today's world, in that "trade-offs" are an example of these tensions. That is, people want privacy but at the same time they will give up privacy to have something they desire in the moment. Finally, calculating viability as a theory and in the research, metrics show that to date, there are over one thousand citations, 44 countries are represented, and 340 contexts used. This article introduces an overview with many more ways CPM can and does open doors to a different prospective on privacy.

\section{Funding sources}


This research did not receive any specific grant from funding agencies in the public, commercial, or not-for-profit sectors.

\section{Conflict of interest statement}

Nothing declared.

\section{Acknowledgements}

Our considerable thanks to Charles Bantz for his work on this article.

References and recommended reading

1. NY Times: Privacy project. https://www.nytimes.com/series/new-york-times-privacyproject New York Times Privacy Project.

2. Barth S, de Jong, M: The privacy paradox - Investigating discrepancies between expressed privacy concerns and actual online behavior - A systematic literature review. Telemat Informat 2017, 34:1038-1058 https://doi:10.1016/j.tele.2017.04.013.

3. Chen HT: Revisiting the privacy paradox on social media with an extended privacy calculus model: The effect of privacy concerns, privacy self-efficacy, and social capital on privacy management. Am Behav Sci 2018, 62:1392-1412 https://doi:10.1177/0002764218792691.

4. Acquisti A, Brandimarte L, Loewenstein G: Privacy and human behavior in the age of information. Science 2015, 347:509-514 https://doi:10.1126/science.aaa1465.

5. Kirwan G: Psychology and security: Utilizing psychological and communication theories to promote safer cloud security behaviors. In The cloud security ecosystem: Technical, legal, business and management issues. Edited by Ko R, Choo R. Syngress; 2015:269-281.

6. Tissera M, Thelijjagoda S, Goonathilake, J: User-centric privacy preservation solution to control third party access in digital databases._Int J Adv Eng Technol Bareilly 2017, 10:30-45.

7. Pope TM: Legal fundamentals of surrogate decision making. Chest 2012, 141:10741081 https://doi.org/10.1378/chest.11-2336.

8. Terry NP: Regulatory disruption and arbitrage in health-care data protection. Yale J Health Policy Law Ethics 2017, 17:143-207.

9. Cho H, Knijnenburg B, Kobsa A, Li Y: Collective privacy management in social media: A cross-cultural validation. ACM T Comput-hum Int 2018, 25:1-33 https://dx.doi.org/10.1145/3193120. 
10. Petronio S: Boundaries of Privacy: Balancing Dialectics of Disclosure. SUNY Press; 2002.

11. Petronio S, Martin J: Ramifications of revealing private information: A gender gap. $J$ Clin Psychol 1986, 42:499-506 https://doi:10.1002/1097-4679(198605)42:3<499::AIDJCLP2270420317>3.0.CO;2-I.

12. Petronio S: Communication Boundary Management: A Theoretical Model of Managing Disclosure of Private Information between Marital Couples. Commun Theor 1991, 11:311-335 https://doi.org/10.1111/j.1468-2885.1991.tb00023.x.

13. Petronio S: Communication privacy management theory: What do we know about family privacy regulation? J Fam Theor Rev 2010, 2:175-196.

14. Petronio S: Brief status report on communication privacy management theory. $J$ Fam Commun 2013, 13:6-14.

15. Petronio S: Communication privacy management theory. In The International Encyclopedia of Interpersonal Communication. Edited by Berger C, Roloff, M. WileyBlackwell; 2015:353-360 https://doi:10.1002/9781118540190.wbeic132.

16. Petronio S: Privacy from a communication science perspective. In The Handbook of Privacy Studies: An Interdisciplinary Introduction. Edited by Sloot B van der, Groot A de. Amsterdam University Press; 2018:387-407.

17. Altman I: Environment and Social Behavior: Privacy, Personal Space, Territory, and Crowding. Brooks/Cole; 1975.

18. Altman I: Privacy regulation: Culturally universal or culturally specific? J Soc Issues 1977, 33:66-84.

19. Schoeman FD: Privacy: Philosophical Dimensions of the Literature. In Philosophical dimensions of privacy: An anthology. Edited by Schoeman FD. Cambridge University Press; 1984:1-33.

20. Petronio S, Gaff C: Managing privacy ownership and disclosure. In Family Communication About Genetics: Theory and Practices. Edited by Gaff C, Bylund C. Oxford University Press; 2010:120-135.

21. *Brannon GE, Rauscher EA: Managing face while managing privacy: Factors that predict young adults' communication about sexually transmitted infections with romantic partners. Health Commun 2018, https://doi:10.1080/10410236.2018.1536951. While communicating with romantic partners about sexually transmitted infections (STIs) can positively effect health outcomes, it is risky for the parties in the conversation. Using Politeness Theory and Communication Privacy Management Theory this study of 374 college students found self-efficacy, intention to communicate about STIs, and willingness to communicate about health predicted face management. The findings also show individuals not only protect their face, but also manage the other's face while managing their own privacy boundaries.

22. Hammonds JR: A model of privacy control: Examining the criteria that predict emerging adults' likelihood to reveal private information to their parents. Western J Comm 2015, 79:591-613 https://doi:10.1080/10570314.2015.1083117.

23. Bute J, Brann M: Co-ownership of private information in the miscarriage context. $J$ Appl Commun Res 2015, 43:23-43 https://doi:10.1080/00909882.2014.982686. 
24. Dickerson D, Buckner M: Communication conundrums: Theories about and tips for effective decanal communication. U Toledo Law Rev 2017, 48:211-240.

25. Smith SA, Brunner SR: To reveal or conceal: Using Communication Privacy Management Theory to understand disclosures in the workplace. Manage Commun $Q$ 2017, 31:429-446 https://doi:10.1177/0893318917692896.

26. *Hernandez R: Understanding sorority women's privacy management about condom use. Qual Health Res 2018, 28:1342-1353 https://doi:10.1177/1049732318766506. This research conducted focus groups with college sorority members to understand how they manage privacy when considering communicating about condoms. These woman developed rule criteria that shaped internal (within the sorority) privacy boundaries including spatial criteria, cohabitation, closeness and trust, perceived similarity, and equal disclosure. On the other hand, their external privacy boundaries were much less permeable especially with parents and health professionals and as they sought to maintain their reputation with other sororities and fraternities.

27. Miller Henningsen ML, Valde KS, Entzminger MJ, Dick DT, Wilcher LB: Student disclosures about academic information: Student privacy rules and boundaries. Commun Rep 2019, 32:29-42 https://doi:10.1080/08934215.2018.1556312.

28. Child JT, Compton CA: A communication privacy management analysis of an end of life admission. In Casing Communication Theory. Edited by Liberman C, Rancer AS, Avtgis TA. Kendall Hunt; 2019:77-86.

29. Kaufmann R, Lane D: Examining communication privacy management in the middle school classroom: Perceived gains and consequences. Educ Res 2014, 56:13-27 https://doi:10.1080/00131881.2013.874145.

30. Goldberg AE, Allen KR, Ellawala T, Ross LE: Male- partnered bisexual women's perceptions of disclosing sexual orientation to family across the transition to parenthood: Intensifying heteronormativity or queering family? Journal of Marital \& Family Therapy 2018, 44:150-164 https://doi:10.1111/jmft.12242.

31. Ebersole DS, Hernandez RA: "Taking good care of our health": Parent-adolescent perceptions of boundary management about health information. Commun $Q 2016$, 64:573-595 https://doi:10.1080/01463373.2016.1176939.

32. Rauscher EA, Durham WT: “As long as you're sure you don't want any more children": Men's collective boundary coordination of information about their affirmative vasectomy decision. Commun Stud 2015, 66:186-203 https://doi:10.1080/10510974.2014.930917.

33. Child JT, Duck AR, Andrews LA,Butauski M, Petronio S: Young adults' management of privacy on Facebook with multiple generations of family members. $J$ Fam Commun 2015, 15:349-367 https://doi:10.1080/15267431.2015.1076425.

34. DeGroot JM, Vik TA: "We were not prepared to tell people yet": Confidentiality breaches and boundary turbulence on Facebook." Comput Hum Behav 2017, 70:351359 https://doi.org/10.1016/j.chb.2017.01.016.

35. Steuber KR, Solomon DH: Relational uncertainty, partner interference, and privacy boundary turbulence: Explaining spousal discrepancies in infertility disclosures. $J$ Soc Pers Relat 2012, 29:3-27 https://doi:10.1177/0265407511406896. 
36. Kennedy-Lightsey CD, Frisby BN: Parental privacy invasion, family communication patterns, and perceived ownership of private information. Commun Rep 2016, 29:7586 https://doi:10.1080/08934215.2015.1048477.

37. Wenzel Egan KA, Hesse C: "Tell me so that I can help you": Private information and privacy coordination issues in context of eldercare. J Fam Commun 2018, 18:217-232. https://doi:10.1080/15267431.2018.1466784.

38. Child JT, Haridakis PM, Petronio S: (2012). Blogging privacy rule orientations, privacy management, and content deletion practices: The variability of online privacy management activity at different stages of social media use. Comput Hum Behav 2012, 28:1859-1872 https://doi: 10.1016/j.chb.2012.05.004.

39. Child JT, Petronio S, Agyeman-Budu EA, Westermann DA: Blog scrubbing: Exploring triggers that change privacy rules. Comput Hum Behav 2011, 27: 2017-2027. https://dx.doi.org/10.1016/j.chb.2011.05.009.

40. McLaren RM, Steuber KR: Emotions, communicative responses, and relational consequences of boundary turbulence. J Soc Pers Relat 2013, 30:606-626 https://doi:10.1177/0265407512463997.

41. Litt E, Hargittai E: A bumpy ride on the information superhighway: Exploring turbulence online. Comput Hum Behav 2014, 36:520-529 https://doi:10.1016/j.chb.2014.04.027.

42. Thorson AR: Investigating adult children's experiences with privacy turbulence following the discovery of parental infidelity. J Fam Commun 2015, 15:41-57 https://doi:10.1080/15267431.2014.980824.

43. Child JT, Starcher SC: Fuzzy Facebook privacy boundaries: Exploring mediated lurking, vague-booking, and Facebook privacy management. Comput Hum Behav 2016, 54:483-490 https://doi:10.1016/j.chb.2015.08.035.

44. McNealy J, Mullis MD: Tea and turbulence: Communication privacy management theory and online celebrity gossip forums. Comput Hum Behav 2019, 92:110-118 https://doi:10.1016/j.chb.2018.10.029.

45. Child JT, Petronio S: Privacy management matters in digital family communication. In Family Communication in the Age of Digital and Social Media. Edited by Bruess CJ. Peter Lang; 2015:32-54 https://doi.org/10.3726/978-1-4539-1668-1.

46. Brockhage K, Phillips KE: (Re)Negotiating our relationship: How contradictions emerge in sibling privacy boundaries. Southern Commun J 2016, 81:79-91 https://doi:10.1080/1041794X.2015.1095231.

47. Venetis MK, Greene K, Magsamen-Conrad K, Banerjee SC, Checton MG, Bagdasarov Z: "You can't tell anyone but...": Exploring the use of privacy rules and revealing behaviors. Commun Monogr 2012, 79:344-365 https://doi:10.1080/03637751.2012.697628.

48. Petronio S, Bantz, C: Controlling the ramifications of disclosure: "Don't tell anybody but .... J Lang Soc Psychol 1991, 10:263-269 https://doi:10.1177/0261927X91104003.

49. Scharp KM, Steuber KR: Perceived information ownership and control: Negotiating communication preferences in potential adoption reunions. Pers Relationship 2014, 21:515-529 https://doi:10.1111/pere.12046. 
50. Rafferty KA, Hutton K, Heller S: "I will communicate with you, but let me be in control": Understanding how parents manage private information about their chronically ill children. Health Commun 2019, 34:100-109 https://doi:10.1080/10410236.2017.1384432.

51. **Bute JJ, Brann M, Hernandez R: Exploring societal-level privacy rules for talking about miscarriage. J Soc Pers Relat 2019, 36:379-399 https://doi:10.1177/0265407517731828.

The study asked why people find it so difficult to discuss miscarriages even though miscarriages are a common experience. By focusing on how societal expectations intersect with privacy rules, the research shows that the societal-level privacy rules such as "keep it behind closed doors" or "no guys should talk about it" shaped perceptions of how the respondents should talk or refrain from talking about their experience.

52. Kam J.A., Fazio K.S., Murillo R.M. (2018). Privacy rules for revealing one's undocumented status to nonfamily members: Exploring the perspectives of undocumented youth of Mexican origin. Journal of Social and Personal Relationships, https://doi:10.1177/0265407518815980.

53. *Millham MH, Atkin D: Managing the virtual boundaries: Online social networks, disclosure, and privacy behaviors. New Media Soc 2018, 20:50-67 https://doi:10.1177/1461444816654465.

In understanding the interplay of online social networks encouraging disclosure while maintaining the ability to disrupt a person's privacy boundaries surrounding their information sets a challenge in understanding the best way to navigate disclosure-privacy issues. Using "Digital Natives" in online social networks, this study aimed to examine privacy beliefs, how valuable the respondents felt their personal, private information was to them and the risks they were willing to take disclosing in an anonymous on online settings. These authors found that if respondents placed a higher premium on personally private information, they were less likely to disclose their private information while visiting online social network sites. The authors also found that using attitudinal measures tended to be stronger predictors of privacy behaviors than were social locators. These findings reinforce that users of social networks do have discernment about management of their private information.

54. Liu Z, Wang X: How to regulate individuals' privacy boundaries on social network sites: A cross-cultural comparison. Inf Manag 2018, 55:1005-1023 https://doi.org/10.1016/j.im.2018.05.006.

55. Morr Serewicz MC, Canary DJ: Assessments of disclosure from the in-laws: Links among disclosure topics, family privacy orientations, and relational quality. $J$ Soc Pers Relat 2008, 25:333-357 https://doi.org/10.1177/0265407507087962.

56. Rueter MA, Connor JJ, Pasch L, Anderson KN, Scheib JE, Koerner AF, Damario M: Sharing information with children conceived using in vitro fertilisation: The effect of parents' privacy orientation. J Reprod Infant Psyc 2016, 34:90-102 https://doi:10.1080/02646838.2015.1067856. 
57. De Wolf R, Willaert K, Pierson J: Managing privacy boundaries together: Exploring individual and group privacy management strategies in Facebook. Comput Hum Behav 2014, 35:444-454 https://doi:10.1016/j.chb.2014.03.010.

58. *Campbell-Salome G. (2018). "Yes they have the right to know, but...": Young adult women managing private health information as dependents. Health Communication, https://doi:10.1080/10410236.2018.1452092.

Framed by Communication Privacy Management theory, 20 young adult women who were covered by their parent's health insurance policy participated in a semi-structured interview. While respondents felt they owned their health information, many also felt by paying parents gained ownership rights. The women utilized gender when managing their privacy by being more open with their mothers. They also would seek to "disclose first" before their parents would receive a benefits statement. The findings support and complicate CPM principles - most importantly asking what is the price of privacy?

59. Osatuyi, B., Passerini, K., Ravarini, A., \& Grandhi, S. A. (2018). "Fool me once, shame on you... then, I learn." An examination of information disclosure in social networking sites. Comput Hum Behav 2018, 83:73-86 https://doi:10.1016/j.chb.2018.01.018.

60. Afifi TD: 'Feeling caught' in stepfamilies: Managing boundary turbulence through appropriate communication privacy rules. J Soc Pers Relat 2003, 20:729-755 https://doi:10.1177/0265407503206002.

61. Bello RS, Brandau-Brown F, Ragsdale JD: Managing boundary turbulence through the use of information manipulation strategies: A report on two studies. Cogent Soc Sci 2016, 2:1-21 https://doi:10.1080/23311886.2016.1195937.

62. *Aloia LS: The emotional, behavioral, and cognitive experience of boundary turbulence. Commun Stud 2018, 69:180-195 https://doi:10.1080/10510974.2018.1426617. Communication Privacy Management Theory predicts the disruption of privacy boundaries produces boundary turbulence. This study examines how 216 college students respond to the magnitude of turbulence (the number of people who received the information). The magnitude of turbulence was positively associated with anger, fear, and sadness, but not associated with happiness. Anger was positively associated with distributive tactics such as attacking or arguing, but not associated with integrative cooperative tactics. Further the association between anger and distributive tactics increased as rumination increased.

63. Hays A, Butauski, M: Privacy, disability, and family: Exploring the privacy management behaviors of parents with a child with autism. Western J Commun 2018, 82:376-391 https://doi:10.1080/10570314.2017.1398834.

64. Ledbetter, A.M. (2019). Parent-child privacy boundary conflict patterns during the first year of college: Mediating family communication patterns, predicting psychosocial distress. Human Communication Research, https://doi:10.1093/hcr/hqy018.

65. Basinger ED, Wehrman EC, McAninch KG: Grief communication and privacy rules: Examining the communication of individuals bereaved by the death of a family 
member. J Fam Commun 2016, 16:285-302

https://doi:10.1080/15267431.2016.1182534.

66. Thorson AR: Adult children's experiences with their parent's infidelity:

Communicative protection and access rules in the absence of divorce. Commun Stud 2009, 60:32-48 https://doi:10.1080/10510970802623591.

67. **Walrave M, Van Ouytsel J, Ponnet K, Temple JR: Sharing and caring? The role of social media and privacy in sexting behaviour. In Sexting: Motives and Risk in Online Sexual Self-presentation. Edited by Walrave M, Van Ouytsel J, Ponnet K, Temple JR. Palgrave Macmillan; 2018:1-17 https://doi:10.1007/978-3-319-71882-8_1.

Sexting is intimate disclosure to another via social media, which is problematic when it occurs under pressure or when the content is further disseminated without authorization. Social media offers persistence, visibility, spreadability and searchability, which increases the risks to the sender. Social media has both benign and toxic disinhibition effects that influences sexting. Using Communication Privacy Management to explain the co-ownership created in sharing intimate information creates a co-responsibility model of sexting that shows the new recipients of a sext message must take responsibility for breaching privacy boundaries and engaging in secondary sexting. 